\title{
Determination of Lipoxygenase Activity in Cereals Grains Using a Silver Nanoparticles Assay
}

\author{
Raybel Muñoz, Jose A. Rodriguez, M. Elena Páez-Hernández, \\ Irais Sánchez-Ortega, and Eva M. Santos \\ Área Académica de Química, Universidad Autónoma del Estado de Hidalgo, Carretera Pachuca-Tulancingo Km. 4.5, \\ 42184 Mineral de la Reforma, HGO, Mexico
}

Correspondence should be addressed to Eva M. Santos; emsantos@uaeh.edu.mx

Received 4 June 2015; Accepted 17 September 2015

Academic Editor: Mallikarjuna N. Nadagouda

Copyright (C) 2015 Raybel Muñoz et al. This is an open access article distributed under the Creative Commons Attribution License, which permits unrestricted use, distribution, and reproduction in any medium, provided the original work is properly cited.

\begin{abstract}
A spectrophotometric method based on the use of silver nanoparticles is presented for the determination of lipoxygenase activity in cereal grains. The method involves the synthesis of prism silver nanoparticles with a maximum absorption at $752 \mathrm{~nm}$, followed by the abatement of the signal as a consequence of the oxidation produced by hydroperoxides generated in the enzymatic reaction. The quantification of the hydroperoxides produced by reaction of lipoxygenase with linoleic acid allows the determination of the enzyme activity in cereal grains. Under optimal conditions, the linear range of the calibration curve ranges from 1.0 to $5.0 \mu \mathrm{M}$, with a limit of detection of $0.34 \mu \mathrm{M}$. The method was validated comparing the results with those obtained by ferrous-xylenol orange method. A relative standard deviation $<5.0 \%$ was obtained in all cases and no significant differences were observed $(p<0.05)$.
\end{abstract}

\section{Introduction}

In recent years, the use of nanoparticles (NPs) in instrumental analysis has enormously increased due to their optic, electric, and chemical properties, which are dependent on their synthesis conditions, size, and shape $[1,2]$. Silver nanoparticles (AgNPs) have some unique optic properties caused by collective excitation of the conduction band electrons of the nanoparticle, producing an absorption in the visible region with large values of molar absorptivity. As a consequence, they can acquire different colors ranging from yellow to blue when they are dispersed. The absorption spectrum is attributed to the surface plasmon resonance [3].

Spectrophotometric assays based on the use of AgNPs have been showed to be useful in the analysis of different type of analytes. The main characteristics of these methods are their simplicity, low cost, and high sampling rate without the use of expensive equipment. The methodologies proposed are based on the changes of the AgNPs by two main principles: the formation of AgNPs aggregates causing a color change in the suspension $[4,5]$ and the modification of size and shape of the AgNPs by the use of oxidizing or reducing analytes $[6,7]$.
One of the common processes in cereals is the lipid oxidation as a consequence of the enzymatic activity of lipoxygenase. This enzyme catalyzes hydroperoxidation of polyunsaturated fatty acids containing cis bonds by molecular oxygen. The substrates involved in this enzymatic reaction are mainly the linoleic, linolenic, and arachidonic acids [8].

The enzymatic activity can be measured determining the lipid hydroperoxides generated during reaction. Lipid hydroperoxides are strong oxidizing agents with high redox potential [9]. Considering the effect of redox compounds in the optical properties of AgNPs, the aim of the present work was to evaluate the use of AgNPs in the quantification of lipoxygenase activity in cereals grains.

\section{Materials and Methods}

2.1. Reagents and Chemicals. All solutions were prepared by dissolving the respective analytical grade reagent in deionized water with a resistivity not less than $18.0 \mathrm{M} \Omega \mathrm{cm}$, provided by a Milli-Q system (Millipore, Bedford, MA, USA). Ascorbic acid, linoleic acid, lipoxidase from Glycine max 
TABLE 1: Factor levels of the central composite design optimization.

\begin{tabular}{lccccc}
\hline Factors & -1.7 & -1.0 & 0.0 & 1.0 & 1.7 \\
\hline$[\mathrm{AgNPs}]_{\text {seeds }}(\mu \mathrm{M})$ & 1.4 & 1.6 & 1.8 & 2.0 & 2.2 \\
{$\left[\mathrm{Ag}^{+}\right](\mu \mathrm{M})$} & 54.0 & 68.6 & 90.0 & 111.4 & 126.0 \\
{$[\mathrm{AA}](\mathrm{mM})$} & 1.0 & 1.2 & 1.5 & 1.8 & 2.0 \\
\hline
\end{tabular}

(soybean), which is the enzyme commonly used to determine lipoxygenase activity, sodium borohydride, sodium citrate tribasic dehydrate, silver nitrate, and Tween 20 were obtained from Sigma Aldrich (St. Louis, MO, USA). Tris(hydroxymethyl)aminomethane and ammonia solution (28-30\%) were from J. T. Baker (Phillipsburg, NJ, USA). Starch, maltose, sucrose, and glucose (Sigma-Aldrich) were tested as interfering compounds in concentration of $1-3 \%$ $(\mathrm{w} / \mathrm{w})$. Cereal samples (barley, rice, and wheat) were bought in local markets in Pachuca de Soto (Hidalgo, Mexico).

2.2. Synthesis of AgNPs. AgNPs were synthesized in two steps. In the first one, seeds AgNPs were obtained through reduction of $\mathrm{Ag}^{+}$using $\mathrm{NaBH}_{4}$. For that purpose, an aliquot of $25 \mathrm{~mL}$ of a solution containing $\mathrm{AgNO}_{3}(0.72 \mathrm{mM})$ and sodium citrate $(0.68 \mathrm{mM})$ were transferred to a beaker. AgNPs were formed by adding $0.6 \mathrm{~mL}$ of $\mathrm{NaBH}_{4}(0.01 \mathrm{M})$ while stirring until the solution became yellow. The solution was prepared weekly and stored in dark conditions at room temperature.

The second step was the synthesis of prism AgNPs. Experimental conditions were evaluated and optimized using multivariate experimental design. A multilevel central composite design was applied to generate an optimal and robust response surface. The variables involved were the seeds AgNPs concentration ([AgNPs]), the silver ion concentration $\left(\left[\mathrm{Ag}^{+}\right]\right)$, and the ascorbic acid concentration (AA). The response surface was mapped and explored using a rotatable three-factor central composite design, with five levels of each factor $(\alpha=1.7)$. Table 1 shows the settings for each control factor used in the optimization experiments. The effects of these variables were examined using MINITAB V15.1 software.

The optimized conditions to synthetize the prism AgNPs were as follows: $10 \mathrm{~mL}$ of water was mixed with $0.05 \mathrm{~g}$ of sodium citrate, $250 \mu \mathrm{L}$ of seed AgNPs, $60 \mu \mathrm{L}$ of $\mathrm{AgNO}_{3}$ $(0.018 \mathrm{M})$, and $150 \mu \mathrm{L}$ of ascorbic acid $(0.1 \mathrm{M})$. The mixture became blue-green after $5 \mathrm{~min}$. This solution was prepared before each analysis.

The UV-Vis spectra of the AgNPs (seeds and prism) were recorded using a Lambda $40 \mathrm{UV}-\mathrm{V}$ is spectrophotometer (Perkin Elmer) and quartz cells $(1 \mathrm{~cm})$. The morphological analysis of AgNPs was performed using a JEOL JEM101 Transmission Electron Microscope (TEM, JEOL Inc., Peabody, MA, USA).

2.3. Synthesis of Hydroperoxides. Ammonium linoleate $(10.20 \mathrm{mM})$ was prepared following the methodology proposed by Pinto et al. [10]. A mixture of $0.0286 \mathrm{~g}$ of linoleic acid, $76.5 \mu \mathrm{L}$ of water, and $23.5 \mu \mathrm{L}$ of ammonia solution was incubated for $30 \mathrm{~min}$ at $60^{\circ} \mathrm{C}$. After that, $200 \mu \mathrm{L}$ of Tween 20 was added and the volume was adjusted to $10 \mathrm{~mL}$ with Tris buffer (0.1 M, pH 6.6).

Hydroperoxides from linoleic acid were obtained by mixing $5 \mathrm{~mL}$ of the solution of ammonium linoleate and $20 \mu \mathrm{L}$ of a solution containing $450 \mathrm{U}$ of lipoxidase from Glycine max (soybean). The reaction was stopped after $30 \mathrm{~min}$ by adjusting the volume to $10 \mathrm{~mL}$ with methanol. The absorbance of the solution was spectrophotometrically measured at $245 \mathrm{~nm}$. The concentration of hydroperoxides $(\mathrm{mM})$ was determined using Lambert-Beer expression where the molar absorptivity had a value of $25 \mathrm{mM}^{-1} \mathrm{~cm}^{-1}$ [10]. Different standards of hydroperoxides were prepared by dilution from the previous solution in the range of $1.5-6.0 \mu \mathrm{M}$.

2.4. Sample Analysis. An amount around $1.2 \mathrm{~g}$ of different cereals (barley, rice, and wheat) was dehusked and the lipoxygenase enzyme was extracted grinding them with a mortar and pestle at $4^{\circ} \mathrm{C}$ and $8 \mathrm{~mL}$ of Tris buffer $(0.1 \mathrm{M}$, $\mathrm{pH}$ 6.6) containing $0.1 \%(\mathrm{v} / \mathrm{v})$ of Tween 20 . The extract was transferred to microcentrifuge tubes and centrifuged for $15 \mathrm{~min}$ at $6000 \mathrm{rpm}$. The liquid phases were collected and protein content was determined using the Bradford method [11].

Lipoxygenase activity was determined using the prism AgNPs suspension. For that purpose, $10 \mathrm{~mL}$ of AgNPs was mixed with $2 \mathrm{~mL}$ of ammonium linoleate $(10.2 \mathrm{mM})$, prepared as previously described, and $70 \mu \mathrm{L}$ of cereal extract. After $5 \mathrm{~min}$, the visible spectrum was obtained in the range of $300-1000 \mathrm{~nm}$. The concentration of the hydroperoxides produced was obtained by interpolation in the calibration line constructed using hydroperoxides from linoleic acid in the interval range of $1.5-6.0 \mu \mathrm{M}$.

2.5. Comparison Method. Lipoxygenase activity in the samples was also determined for comparative purposes using the ferrous-xylenol orange method. The reagent for the assay consisted of a solution containing $\mathrm{FeSO}_{4} \cdot 7 \mathrm{H}_{2} \mathrm{O}(0.25 \mathrm{mM})$, perchloric acid $(0.22 \mathrm{M})$, and xylenol orange $(37.5 \mu \mathrm{M})$ in methanol: water $(9: 1, \mathrm{v}: \mathrm{v})$. For each analysis, $1.0 \mathrm{~mL}$ of the reagent solution was mixed with $1.0 \mathrm{~mL}$ of Tris buffer $(\mathrm{pH} 6.6$, $0.01 \mathrm{M}), 25 \mu \mathrm{L}$ of ammonium linoleate $(10.2 \mathrm{mM})$, and $25 \mu \mathrm{L}$ of the cereal extract. After $5 \mathrm{~min}$ of reaction, the absorbance was measured at $560 \mathrm{~nm}$. The hydroperoxides generated were determined by interpolation in the calibration line using standards solutions of hydroperoxides of linoleic acid in the range of 0.5 to $5 \mu \mathrm{M}$, and were analyzed in equal conditions compared to the samples [12]. Each analysis was performed in triplicate.

\section{Results and Discussion}

The morphological changes of AgNPs prepared were analyzed by transmission electron microscopy. Figure 1(a) shows the image obtained for seed nanoparticles, where it can be observed that the initial particles were spherical with diameters ranging from 18 to $25 \mathrm{~nm}$. Prism AgNPs were 


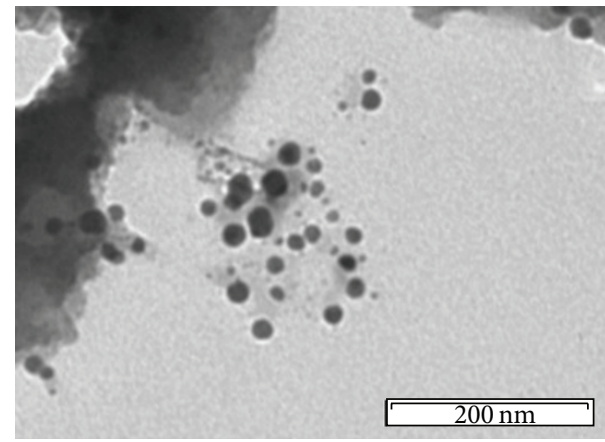

(a)

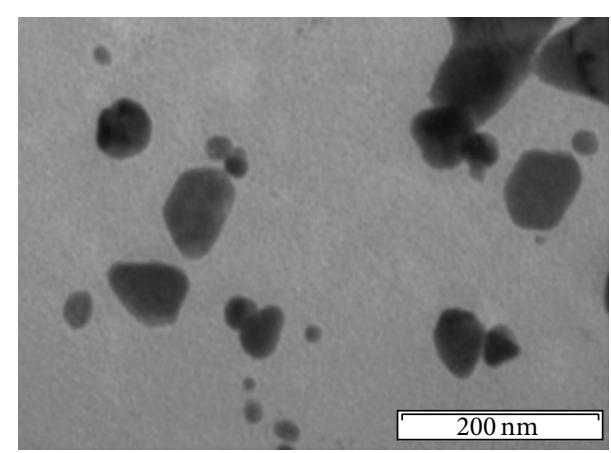

(b)

FIgURE 1: Transmission electron microscopy images showing the changes of AgNPs morphology. (a) Seed AgNPs and (b) prism AgNPs.

grown by the addition of ascorbic acid through reduction of the $\mathrm{Ag}^{+}$to $\mathrm{Ag}^{0}$, modifying its color from yellow to green because of the dispersion. The micrograph (Figure 1(b)) revealed that the obtained prisms AgNPs presented lengths varying from 19 to $93 \mathrm{~nm}$.

Morphology changes are also reflected in the visible spectra. The spectra obtained for seed AgNPs exhibited a peak at $395 \mathrm{~nm}$ (Figure 2(a)), corresponding to the plasmon resonance of small spherical particles. The spectra obtained for prism AgNPs showed a maximum at $752 \mathrm{~nm}$; this signal is assigned to the in-plane plasmon resonance, indicating that prism nanoparticles were formed [13]. Lipids have large values of molar absorptivity at $395 \mathrm{~nm}$ [14], and then the sample matrix could interfere if the oxidation reaction at this wavelength uses seed AgNPs. Prism AgNPs were therefore selected for the analysis of hydroperoxides since the lipids do not have significant absorption at $752 \mathrm{~nm}$.

Once the AgNPs are selected, a central composite design was used for the study of the synthesis variables of the prism AgNPs. The control variables involved were the ascorbic acid concentration (AA) and the silver ion concentration $\left(\left[\mathrm{Ag}^{+}\right]\right)$, which controls the size of the nanoparticles, and the seed concentration (AgNPs) related to ensure the aggregation of the nanoparticles [15]. The output variable was the peak height at $752 \mathrm{~nm}$ (absorbance units, A.U.) obtained from the synthesis of the AgNPs in the conditions from the design matrix. The response surface was mapped and explored using a rotatable three-factor central composite design, with five levels of each factor $(\alpha=1.7)$. The experimental matrix used during optimization is shown in Table 2. All experiments were carried out randomly.

A statistically significant linear model accounting for $75 \%$ of the variance fitted the data. The response surface fitted the following equation (linear model):

$$
\begin{aligned}
\text { Absorbance }= & 0.762-0.008[\mathrm{AgNPs}]+0.185\left[\mathrm{Ag}^{+}\right] \\
& -0.028[\mathrm{AA}] .
\end{aligned}
$$

Analysis of variance of the results showed that concentration of $\mathrm{Ag}^{+}$was the only factor with a statistically significant effect on the signal value $(p<0.05)$. Analysis of the residuals from the regression model and the lack of fit test revealed

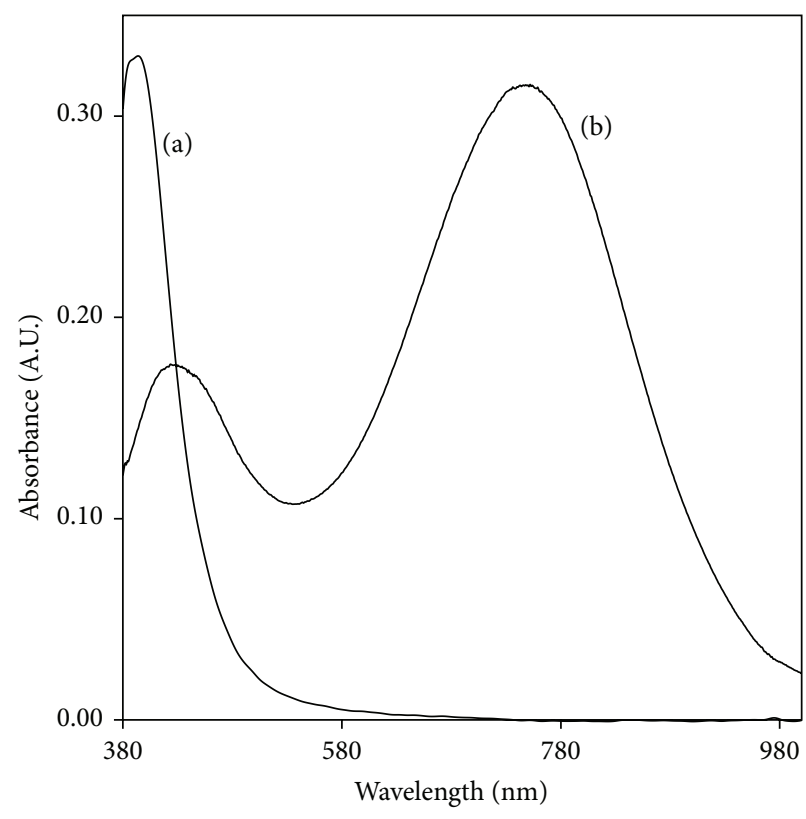

FIgURE 2: Visible spectra of (a) seed AgNPs and (b) prism AgNPs.

that the linear model could be an adequate surface over the experimental interval studied.

The response surfaces obtained at fixed $\left[\mathrm{Ag}^{+}\right]$of 54.0 and $126.0 \mu \mathrm{M}$ are shown in Figure 3. It is clear that absorbance of the signal increased with $\left[\mathrm{Ag}^{+}\right]$. In contrast, the results indicated that decreasing the concentrations of seed AgNPs and AA hardly increased the peak height. This behaviour is attributed to the influence of silver ions on prism AgNPs growth and, also, to the effect of AA concentration. AA concentrations higher than $1.0 \mathrm{mM}$ induced AgNPs aggregations through charge-charge interaction as a consequence of the unstable surface state [16]. The combination selected as optimum was as follows: [AgNPs], $1.41 \mu \mathrm{M} ;\left[\mathrm{Ag}^{+}\right], 126 \mu \mathrm{M}$; and $[\mathrm{AA}], 1.0 \mathrm{mM}$. Under these conditions a predicted signal of 1.187 A.U. (at $752 \mathrm{~nm}$ ) was obtained, very close to the experimental value (1.145 A.U.). 
TABLE 2: Design matrix and responses for the central composite design.

\begin{tabular}{lccc}
\hline$[\mathrm{AgNPs}]_{\text {seeds }}$ & {$\left[\mathrm{Ag}^{+}\right]$} & {$[\mathrm{AA}]$} & Resp (A.U.) \\
\hline-1.0 & -1.0 & -1.0 & 0.717 \\
1.0 & -1.0 & -1.0 & 0.501 \\
-1.0 & 1.0 & -1.0 & 1.080 \\
1.0 & 1.0 & -1.0 & 0.884 \\
-1.0 & -1.0 & 1.0 & 0.580 \\
1.0 & -1.0 & 1.0 & 0.634 \\
-1.0 & 1.0 & 1.0 & 1.043 \\
1.0 & 1.0 & 1.0 & 0.896 \\
-1.7 & 0.0 & 0.0 & 0.545 \\
1.7 & 0.0 & 0.0 & 0.777 \\
0.0 & -1.7 & 0.0 & 0.422 \\
0.0 & 1.7 & 0.0 & 1.048 \\
0.0 & 0.0 & -1.7 & 0.872 \\
0.0 & 0.0 & 1.7 & 0.660 \\
0.0 & 0.0 & 0.0 & 0.734 \\
0.0 & 0.0 & 0.0 & 0.806 \\
0.0 & 0.0 & 0.0 & 0.696 \\
0.0 & 0.0 & 0.0 & 0.766 \\
0.0 & 0.0 & 0.0 & 0.919 \\
0.0 & 0.0 & 0.0 & 0.807 \\
\hline
\end{tabular}

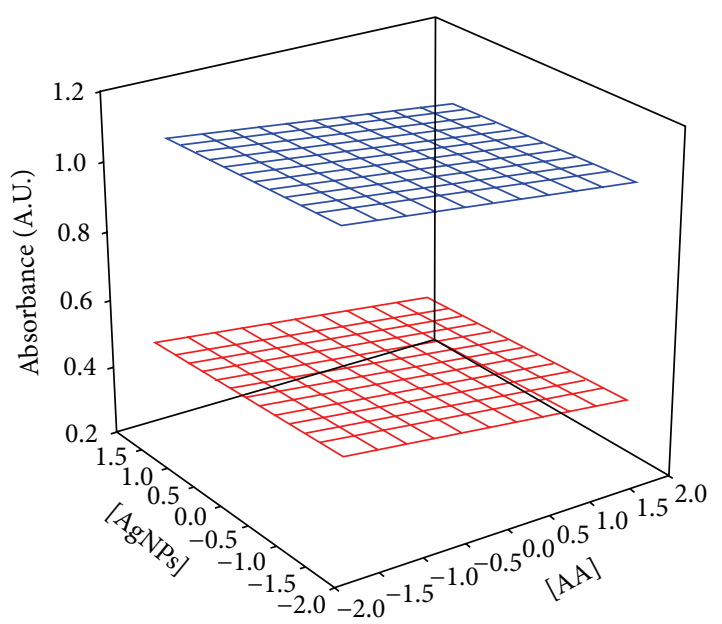

FIgURE 3: Optimal response surfaces (as peak height, A.U.) at $\left[\mathrm{Ag}^{+}\right]$ of $-1.7(54.0 \mu \mathrm{M}$, red) and $1.7(126.0 \mu \mathrm{M}$, blue $)$.

After establishing the optimal concentration to produce the prism AgNPs, the calibration plot for hydroperoxides from linoleic acid was obtained (Figure 4). Three replicate measurements of each standard solution were made and the mean values were used for calculations. A lineal dependence (Absorbance $=0.024( \pm 0.034)-$ $0.118( \pm 0.009)$ [hydroperoxide]) between the peak height and the hydroperoxide content was found in the range 1.02$5.20 \mu \mathrm{M}$ with a detection limit of $0.37 \mu \mathrm{M}$. The detection limit was calculated according to the IUPAC criteria, that is, 3.29 times the value of se/ $b_{1}$, where se is the square root of the

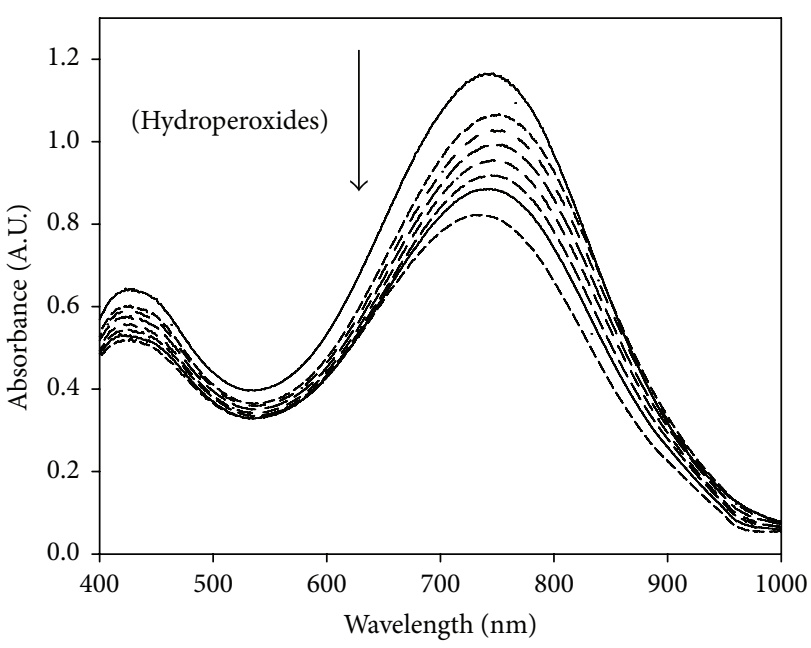

FIGURE 4: Visible spectra of prism AgNPs suspensions for increasing hydroperoxides concentrations from 1.0 to $5.0 \mu \mathrm{M}$.

residual variance of the standard curve and $b_{1}$ is the analytical sensitivity [17].

The intermediate precision of the procedure, expressed as the relative standard deviation of three determinations made on different AgNPs on a $3.0 \mu \mathrm{M}$ standard solution of hydroperoxides, was $4.3 \%$. The repeatability of the signal was below 5\% RSD for all standard solutions and samples.

The presence of carbohydrates can be a potential interference [18]. In this way, the effect of glucose, maltose, sucrose, and starch, carbohydrates usually present in cereal grains extracts, was studied. Absorbance of prism AgNPs suspensions containing a hydroperoxides concentration of $3.0 \mu \mathrm{M}$ and the potentially interfering element at $1 \%(\mathrm{w} / \mathrm{v})$ were analyzed. The added element was considered an interferent when a variation in the signal greater than $\pm 5 \%$ comparing to the response without the carbohydrate was observed. The results showed that starch interfered in the determination of the hydroperoxides at this concentration. Sample amounts and extracts were calculated in order to minimize the interference of starch.

The proposed method was used to determine lipoxygenase activity in cereal grains. Table 3 shows the results obtained. In order to validate the results, the activity of the enzyme in the extracts was also determined by the ferrousxylenol orange method. The results obtained by both methods were compared using a $t$-test. The values of calculated $t$ were then compared to a critical value for 4 degrees of freedom at the $95 \%$ confidence level $\left(t_{\text {crit }}=2.78\right)$. No significant differences were seen between the results obtained with each method. The values obtained for lipoxygenase activity in rice grains were in the same order compared to those obtained for similar samples [12].

\section{Conclusions}

In the present work, a methodology for determination of the activity of lipoxygenase in cereal grains based on the oxidation of prism AgNPs was proposed. The best conditions 
TABLE 3: Lipoxygenase activity (mean and relative standard deviation $n=3$ ) in cereal grains after 12 minutes of reaction (expressed in $\mu \mathrm{M}_{\text {hydroperoxides }} \mathrm{min}^{-1} \mathrm{mg}^{-1}$ protein $)$.

\begin{tabular}{lccr}
\hline Sample & \multicolumn{2}{c}{ Lipoxygenase activity $\left(\mu \mathrm{M}_{\text {hydroperoxides }} \mathrm{min}^{-1} \mathrm{mg}^{-1}{ }_{\text {protein }}\right)$} & $t_{\text {calc }}$ \\
& Prism AgNPs & Ferrous-xylenol orange & 2.19 \\
Barley & $0.08(3.38)$ & $0.07(5.53)$ & 0.27 \\
Rice & $1.32(2.60)$ & $1.31(2.28)$ & $0.08(3.78)$ \\
Wheat & $0.07(3.11)$ & 0.41 & \\
\hline
\end{tabular}

for the synthesis of prism AgNPs were [AgNPs], $1.41 \mu \mathrm{M}$; $\left[\mathrm{Ag}^{+}\right], 126 \mu \mathrm{M}$; and [AA], $1.0 \mathrm{mM}$.

Thus, the proposed spectrophotometric methodology is an alternative to the analysis of analytes with oxidant properties in the food industry because of its analytical precision and accuracy which are similar to other methodologies.

\section{Conflict of Interests}

The authors declare that there is no conflict of interests regarding the publication of this paper.

\section{Acknowledgments}

The authors wish to thank CONACyT (Project INFR-2014227999) for the financial support. Jose A. Rodriguez, M. Elena Páez-Hernández, and Eva M. Santos gratefully thank the SNI for the distinction of their membership.

\section{References}

[1] C. Wang, M. Luconi, A. Masi, and L. Fernandez, "Silver nanoparticles as optical sensors," in Silver Nanoparticles, D. P. Perez, Ed., chapter 12, InTech, Rijeka, Croatia, 2010.

[2] J. J. Mock, M. Barbic, D. R. Smith, D. A. Schultz, and S. Schultz, "Shape effects in plasmon resonance of individual colloidal silver nanoparticles," Journal of Chemical Physics, vol. 116, no. 15, pp. 6755-6759, 2002.

[3] V. Amendola, O. M. Bakr, and F. Stellacci, "A study of the surface plasmon resonance of silver nanoparticles by the discrete dipole approximation method: effect of shape, size, structure, and assembly," Plasmonics, vol. 5, no. 1, pp. 85-97, 2010.

[4] D. Vilela, M. C. González, and A. Escarpa, "Sensing colorimetric approaches based on gold and silver nanoparticles aggregation: chemical creativity behind the assay. A review," Analytica Chimica Acta, vol. 751, pp. 24-43, 2012.

[5] V. K. Gasparyan and I. L. Bazukyan, "Lectin sensitized anisotropic silver nanoparticles for detection of some bacteria," Analytica Chimica Acta, vol. 766, pp. 83-87, 2013.

[6] J. Tashkhourian, M. R. Hormozi-Nezhad, and J. Khodaveisi, "Application of silver nanoparticles and principal componentartificial neural network models for simultaneous determination of levodopa and benserazide hydrochloride by a kinetic spectrophotometric method," Spectrochimica Acta Part A: Molecular and Biomolecular Spectroscopy, vol. 82, no. 1, pp. 2530, 2011.

[7] M. M. Maye, L. Han, N. N. Kariuki et al., "Gold and alloy nanoparticles in solution and thin film assembly: spectrophotometric determination of molar absorptivity," Analytica Chimica Acta, vol. 496, no. 1-2, pp. 17-27, 2003.
[8] P. J. Barnes, Lipids in Cereal Technology, Academic Press, New York, NY, USA, 1983.

[9] E. H. Oliw, F. Jernerén, I. Hoffmann, M. Sahlin, and U. Garscha, "Manganese lipoxygenase oxidizes bis-allylic hydroperoxides and octadecenoic acids by different mechanisms," Biochimica et Biophysica Acta-Molecular and Cell Biology of Lipids, vol. 1811, no. 3, pp. 138-147, 2011.

[10] M. D. C. Pinto, A. Tejeda, A. L. Duque, and P. Macías, "Determination of lipoxygenase activity in plant extracts using a modified ferrous oxidation-xylenol orange assay," Journal of Agricultural and Food Chemistry, vol. 55, no. 15, pp. 5956-5959, 2007.

[11] M. M. Bradford, "A rapid and sensitive method for the quantitation of microgram quantities of protein utilizing the principle of protein-dye binding," Analytical Biochemistry, vol. 72, no. 1-2, pp. 248-254, 1976.

[12] T. Timabud, J. Sanitchon, and P. Pongdontri, "A modified ferrous oxidation-xylenol orange assay for lipoxygenase activity in rice grains," Food Chemistry, vol. 141, no. 3, pp. 2405-2411, 2013.

[13] H. Jia, W. Xu, J. An, D. Li, and B. Zhao, "A simple method to synthesize triangular silver nanoparticles by light irradiation," Spectrochimica Acta A: Molecular and Biomolecular Spectroscopy, vol. 64, no. 4, pp. 956-960, 2006.

[14] M. Casale, P. Oliveri, C. Casolino et al., "Characterisation of PDO olive oil chianti classico by non-selective (UV-visible, NIR and MIR spectroscopy) and selective (fatty acid composition) analytical techniques," Analytica Chimica Acta, vol. 712, no. 27, pp. 56-63, 2012.

[15] D. M. Ledwith, A. M. Whelan, and J. M. Kelly, "A rapid, straightforward method for controlling the morphology of stable silver nanoparticles," Journal of Materials Chemistry, vol. 17, no. 23, pp. 2459-2464, 2007.

[16] J. Roh, J. Yi, and Y. Kim, "Rapid, reversible preparation of sizecontrollable silver nanoplates by chemical redox," Langmuir, vol. 26, no. 14, pp. 11621-11623, 2010.

[17] M. Thompson, S. L. R. Ellison, and R. Wood, "Harmonized guidelines for single-laboratory validation of methods of analysis (IUPAC Technical Report)," Pure and Applied Chemistry, vol. 74, no. 5, pp. 835-855, 2002.

[18] P. Raveendran, J. Fu, and S. L. Wallen, "Completely 'green" synthesis and stabilization of metal nanoparticles," Journal of the American Chemical Society, vol. 125, no. 46, pp. 13940-13941, 2003. 

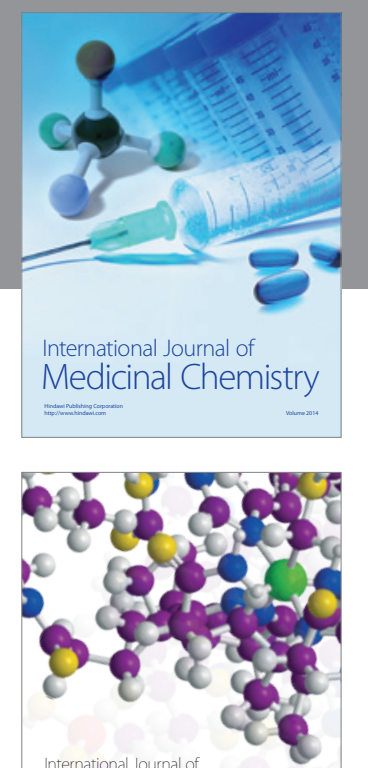

\section{Carbohydrate} Chemistry

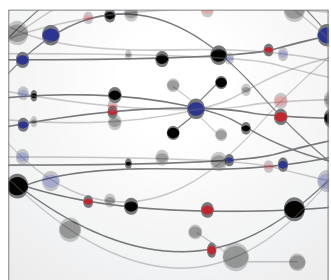

The Scientific World Journal
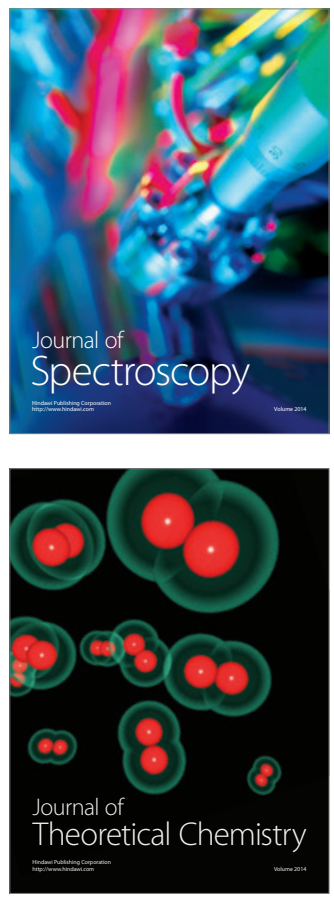
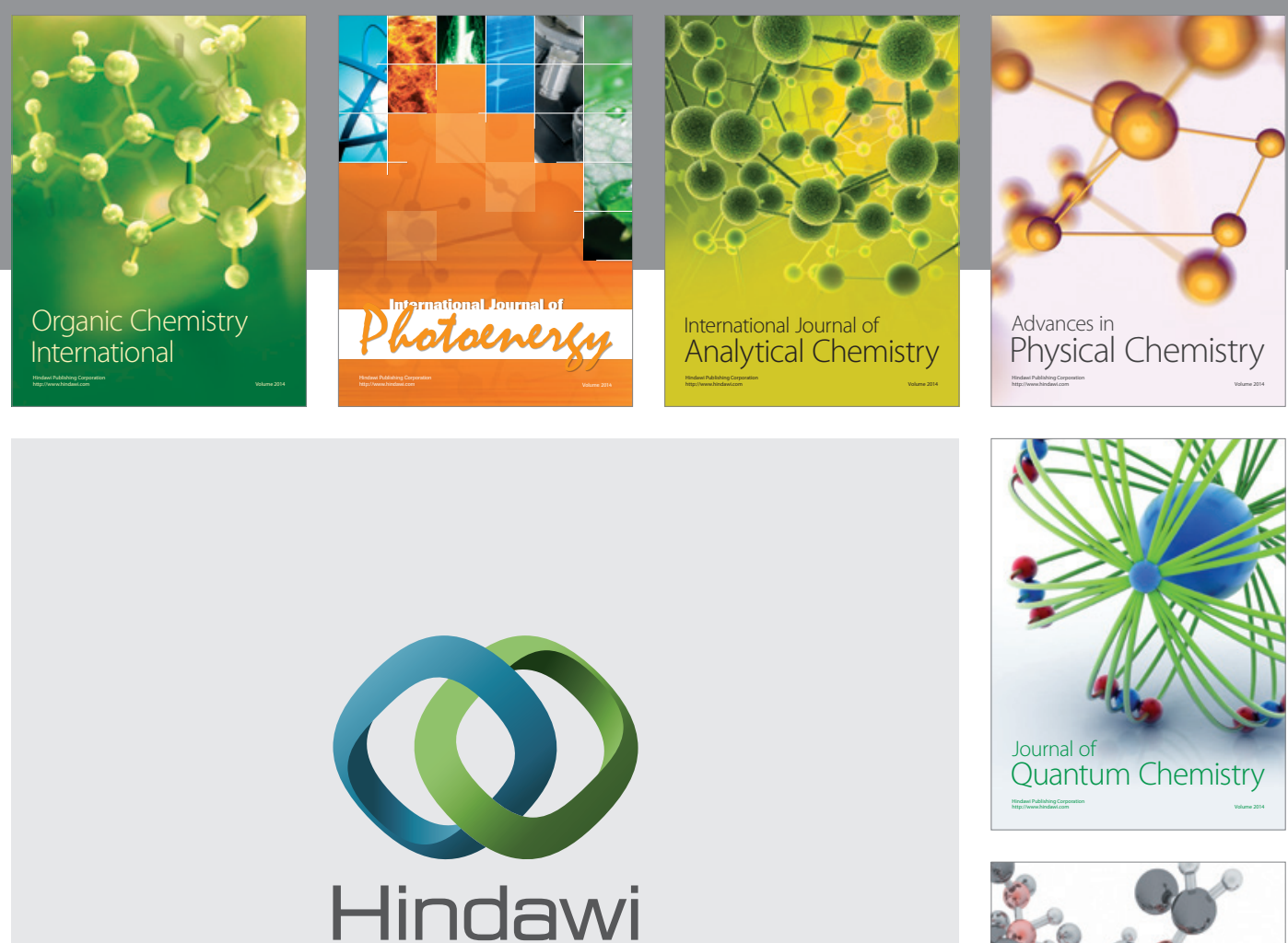

Submit your manuscripts at

http://www.hindawi.com

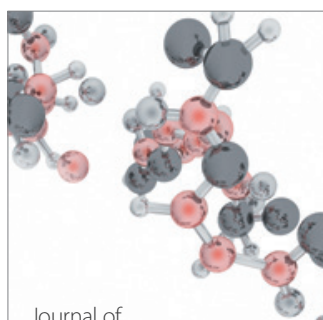

Analytical Methods

in Chemistry

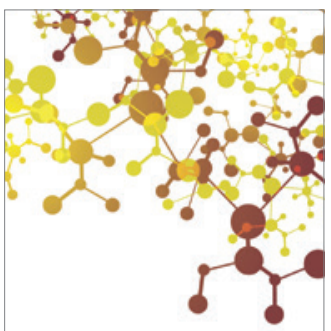

Journal of

Applied Chemistry

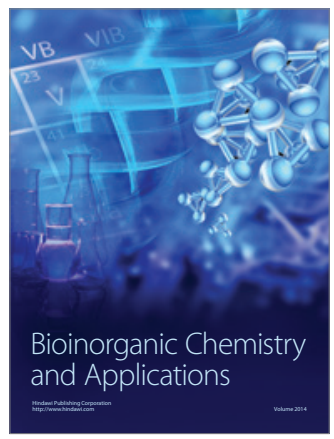

Inorganic Chemistry
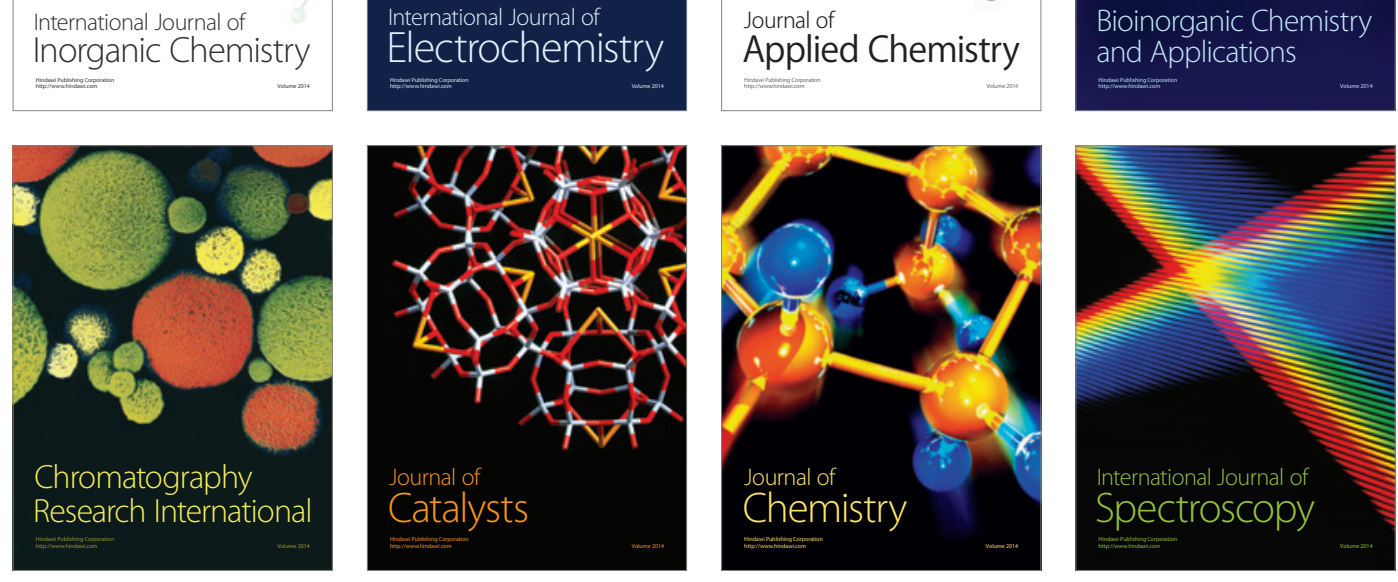